\title{
A Novel Recombinant Chimeric Proteinous Bio- adhesive Consisting of Mussel Foot Protein 3, 5 and Curli Proteins GvpA and CsgA Expressed in Pichia Pastoris
}

\author{
Nazanin Bolghari \\ Islamic Azad University \\ Hadi Habibollahi \\ Islamic Azad University \\ Masoumeh Anvari \\ Islamic Azad University \\ Hosein Shahsavarani ( $\nabla$ hosein.shahsavarani@gmail.com ) \\ Pasteur Institute of Iran https://orcid.org/0000-0002-8123-0857
}

Original article

Keywords: bioadhesive proteins, fusion proteins, GvpA, CsgA, Mfp

Posted Date: July 8th, 2021

DOl: https://doi.org/10.21203/rs.3.rs-640628/v1

License: (c) (i) This work is licensed under a Creative Commons Attribution 4.0 International License.

Read Full License 


\section{Abstract}

Despite various efforts to produce strong recombinant bio-adhesive proteins for medical purposes, efficient production of a safe and feasible bio-glue is not yet a commercial reality due to the weak properties or low expression level. Here, a feasible expression system has been developed to produce strong recombinant fusion protein using Mfp3 and Mfp5 along with two curli proteins, GvpA and CsgA expressed under the control of alcohol oxidase (AOX1) promoter for high-level production in P. pastoris using pPICZa vector. Purified chimeric proteins were first evaluated using western blotting and its remaining dopa were measured in the modified proteins by NBT assay. We further elucidated mechanistic properties of obtained adhesive protein assembly in various $\mathrm{pH}$ based on its different subunits using atomic force microscopy (AFM) when adsorbed onto the mica surface. We found that combinational structural features of subunits and post-translational changes during expression in yeast host have led to potent adherence due to higher dopa residues majorly in acidic condition and tetrad complex that is higher than that of earlier reports in prokaryotic systems. We believe that our obtained chimeric protein resulted through fusion of GvpA and CsgA proteins with dopa-containing Mfp proteins expressed in the methylotrophic yeast, $P$. pastoris, not only presents a candidate for future biomedical applications, but also provides novel biological clues using for high-performance bioinspired biomaterials designation.

\section{Key Points}

- A chimeric bioinspired adhesive protein has been generated for use in wet condition

- Enhanced adhesion strength of chimeric protein due to the curli proteins GvpA and CsgA

- Amyloid structure of GvpA and CsgA led to efficient self-assembly of obtained protein

\section{Introduction}

The use of adhesive materials for the repair of tissues following surgery or trauma have been recently absorbed high attention to be replaced traditional methods such as suture, wiring or staples. Most of the surgical adhesives employed by operations are cyanoacrylate derivatives, which have still numerous considerations like cytotoxicity, inflammatory reaction or operational complexities (Choi et al.2011). Another type of e wound closure generally applied in surgery is animal derived glues, which have a key challenges of safety concerns or non-adequate bond toughness. In spite of tremendous efforts to develop adhesives with broad applications in different tissues or non-tissue surfaces, the safe and outstanding material for tissue adhesion could not yet reach an industrial reality to meet different clinic requirements. (Rebnegger et al .2014)

Therefore, bioinspired recombinant bio adhesive recombinant protein production has been suggested to address aforementioned challenges with less drawbacks such as safety issues, need to further cosmetic operation or any allergic reactions (Cha et al .2009). Recent advances in the biomimetic research have recently led to design of various novel recombinant proteinaceous glues capable of satisfying specific demands of both biomedical and technical fields through cloning and expression of the natural adhesive 
proteins (Deming et al.1999). Numerous marine organisms such as mussels and barnacles are great sources of novel water-resistant adhesive biomaterials that are expected to make adequate bonding toughness that support physiological conditions, where tissues are exposed to excessive moisture and body fluids due to their waterproof properties (Choi et al.2011). These waterborne bio-adhesives are almost were secreted to form holdfast filaments known as the byssus, where they are specifically adapted for functions that include wet adhesion and protective covers (Deming et al.1999; Priemel et al .2017).

Mussel foot proteins (Mfp-2, $-3 \mathrm{~S},-3 \mathrm{~F},-4,-5$ and -6 ) are a group of bioinspired adhesive proteins in the byssal adhesive plaque of the Mytilus species that was produced, secreted and solidified to provide tenacious anchoring to different substrates in harsh underwater environment (Yu et al.2013). Amongst them, Mfp3 is a protein with low molecular weight in two fast and slow versions, with Tyrosine residues that are post-translationally modified to DOPA whereas, Mfp- 5 is small, with high Glycine and Lysine content that Mfp-5 plays a key role in adhesion process (Rahimnejad et al .2017; Rebnegger et al .2014). In spite of extensive research on characterization and recombinant production of Mfp-3 and Mfp-5, functional cost effective self-assembled glue not yet achieved. Though imitation of the unique wet adhesion ability of proteinaceous adhesives with stronger intermolecular interactions in surface adhesion properties successfully obtained by combination of prokaryotic curli proteins such as CsgA from E. coli and Mfp proteins but pathogenicity of its source was still limited its application for biomedical purposes.

It thus suggested that using another safe cross-linking proteins from nonpathogenic origin will possibly improve its adhesion for biomedical applications without any safety concern. GvpA is the amyloid-like fibers in Cyanobacterium Anabaena that sustain the hydrostatic pressure experienced by the cells in the ocean (Pfeifer 2012; Hayes et al .1992). Exploiting GvpA can plays the cohesive role to maintain the structure of obtaining chimeric protein to the acceptable stability/toughness of the adhesion level for using in wet or humid environments such as human body. In present study, first combinational structural features of subunits and post-translational changes as a result of low $\mathrm{pH}$ during expression of the fusion of Mfp3 with GvpA genes and Mfp5 with CsgA in the yeast, P. pastoris has been examined. Finally, we have assessed and compares adhesion properties of the fused adhesive proteins separately.

\section{Materials And Methods}

\section{Strains, plasmids, enzymes, reagents}

Escherichia coli strain TOP 10 (Invitrogen) was used as a host for molecular cloning of DNA in pPICZa (Invitrogen) and propagation of recombinant expression vectors. P. pastoris strain GS115 (Invitrogen) was used for heterologous protein expression. All media and protocols for $P$. pastoris are described in the $P$. pastoris expression manual (Invitrogen). All of molecular biology enzymes, antibiotics, DNase/RNasefree, and distilled water were purchased from Thermo Fisher Scientific Corporation, USA. Other chemicals were procured from Sigma-Aldrich Corporation, USA.

\section{DNA preparation and cloning of Mfp5- CsgA and Mfp3- GvpA}


Genes complete nucleotide sequences were retrieved from the NCBI gene bank. The coding sequence of the Mfp5- CsgA and Mfp3- GvpA genes including a GS linker inserted between EcoRI and Xho/ restriction sites fused to a histidine-tag in the pPICZa vector and synthesized (Biomatik Co, Canada). To confirm correct insertion of Mfp5- CsgA and Mfp3- GvpA polymerase chain reaction (PCR) was done using primers listed in Table 1. The recombinant plasmid was transformed into competent $E$. coli TOP10F' by using heat shock method. (Dolgin et al.2013). It was grown in either Luria-Bertani broth or on LuriaBertani agar, supplemented with zeocin $(50 \mu \mathrm{g} / \mathrm{mL})$ when required. Several positive clones were selected and sent to a commercial laboratory for sequencing to confirm the complete nucleotide sequence of the gene insert. Transformation of $P$. pastoris with the recombinant $\mathrm{pPICZa-Mfp}$ was adopted according to the manufacturer's protocol of the EasySelect ${ }^{\text {TM }}$ P. pastoris Expression Kit (Invitrogen, Carlsbad, CA) (Safder et al .2018). Positive recombinant $P$. pastoris clones were selected for expression.

\section{Transform genes to Pichia pastoris competent cells}

The selected expression plasmid was linearized with Sac I (New England BioLabs, USA) and then transformed into $P$. pastoris by electroporation. Transformants were first screened from YPDS ( $1 \%$ yeast extract, $2 \%$ peptone, $2 \%$ dextrose, $1 \mathrm{M}$ sorbitol, $2 \%$ agar) plates containing Zeocin ${ }^{\text {TM }}$ at a final concentration of $100 \mu \mathrm{g} \mathrm{mL}^{-1}$, then on YPDZ plates (1\% yeast extract, $1 \%$ peptone, $1 \%$ dextrose and $2 \%$ agar containing Zeocin at final concentrations of 150,300 , and $500 \mu \mathrm{g} \mathrm{mL}^{-1}$ ) in order to screen for higher copy numbers of the targeted gene. Recombinant strains producing mannan endo-1,4- $\beta$-mannosidase were further confirmed by BMGY-Azo plates (1\% yeast extract, $2 \%$ peptone, $100 \mathrm{mM}$ potassium phosphate $\mathrm{pH} 6.0,1.34 \% \mathrm{YNB}, 4 \times 10^{-5} \%$ biotin, $0.5 \%$ methanol, $2 \%$ agar and $0.3 \%$ Azo-carob galactomannan).

\section{Expression in P. pastoris}

YPD growth medium containing yeast extract (1\%), peptone (2\%), and glucose (2\%) was inoculated with single colonies of $P$. pastoris $(200 \mathrm{ml})$. The cells were cultured at $30^{\circ} \mathrm{C}$ for $36 \mathrm{~h}$. The cells were then collected by centrifugation for $10 \mathrm{~min}$ at $3000 \times \mathrm{g}, 4^{\circ} \mathrm{C}$ and resuspended to an approximate $\mathrm{OD}_{600}$ of 2 in $300 \mathrm{ml}$ of BMGY Buffered glycerol - complex medium (.1\% yeast extract . $2 \%$ peptone, $100 \mathrm{mM}$ potassium phosphate $\mathrm{Ph} 6.0,1.34 \%$ YNB, $4 * 10$ biotin $1 \%$ glycerol or $0.5 \%$ methanol) were supplemented with $0.5 \mu \mathrm{M}$ $\delta$-aminolevulinic acid, trace element $(250 \mu \mathrm{l} /$ liter $)$ and zeocin $(100 \mathrm{ng} / \mathrm{ml})$. Cells were grown at $29^{\circ} \mathrm{C}$ at agitation rate of $200 \mathrm{rpm}$ and induced for $96 \mathrm{~h}$ by adding methanol $(0.5 \%)$ every $24 \mathrm{~h}$. After $96 \mathrm{~h}$, the cells were harvested by centrifugation at $3000 \times \mathrm{g}$ for $10 \mathrm{~min} 4^{\circ} \mathrm{C}$. Cells were resuspended in breaking buffer (50 mM sodium phosphate, $\mathrm{pH} 7.4,1 \mathrm{mM}$ EDTA, 5\% ( $\mathrm{v} / \mathrm{v}$ ) glycerol, $2 \mathrm{mM}$ DTT, and $1 \mathrm{mM}$ protease inhibitor). The cell suspension was mixed with an equal volume of acid-washed glass beads $(0.5 \sim 0.75$ $\mathrm{mm}$ in diameter) and disrupted by vortexing ( $830 \mathrm{~s}$ at $4{ }^{\circ} \mathrm{C}$ with cooling on ice for $30 \mathrm{~s}$ between the cycles). The lysate was separated from cell debris and glass beads by centrifugation at $10,000 \times \mathrm{g}$ for 8 min at $4{ }^{\circ} \mathrm{C}$. The supernatant was centrifuged at $20,000 \times \mathrm{g}$ at $4^{\circ} \mathrm{C}$ for $1 \mathrm{~h}$ and then, the microsomal pellet was resuspended in breaking buffer and stored at $-80^{\circ} \mathrm{C}$. 


\section{SDS - PAGE and Western blot.}

Extracted proteins were separated by sodium dodecyl sulfate-polyacrylamide gel electrophoresis (SDSPAGE) on $10 \%$ polyacrylamide gels. Electrophoresis was performed at $40 \mathrm{~mA}$ and $100 \mathrm{~V}$ and after that, SDS-PAGE gel was stained with Coomassie Brilliant Blue solution (Bio-Rad). For Western blot, the gel was electrophoretically transferred onto polyvinylidene difluoride (PVDF) membrane. Membranes were blocked in $5 \%(\mathrm{w} / \mathrm{v})$ non-fat dried milk in Tris-buffered saline with $0.1 \%$ tween 20 (TBST) for $1 \mathrm{~h}$ at $4^{\circ} \mathrm{C}$. Membranes were then incubated overnight with anti-his-tag antibody at a 1:1000 dilution in TBST. The membrane was incubated with horseradish peroxidase (HRP) -conjugated goat anti-mouse IgG antibody. Proteins were visualized by an enhanced chemiluminescence method using ChemiDoc XRS (Multi-Copy Pichia Expression Kit.2010).

\section{Purification of proteins}

For protein purification, we used the affinity HisTag purification method. For the purification of His-tag fused AAT, the supernatant was applied to a nickel-immobilized chelating sepharose fast flow column (Amersham, Biosciences). For this purpose, supernatant was first diluted with an equal volume of $2 \mathrm{X}$ binding buffer ( $50 \mathrm{mM} \mathrm{NaH}_{2} \mathrm{PO}_{4}, 500 \mathrm{mM} \mathrm{NaCl}, 10 \mathrm{mM}$ imidazole, $\mathrm{pH}=7.4$ ) and then loaded on to the column. After passing the wash buffer $\left(50 \mathrm{mM} \mathrm{NaH}_{2} \mathrm{PO}_{4}, 500 \mathrm{mM} \mathrm{NaCl}\right.$, a gradient of imidazole from 20 to $40 \mathrm{mM}$, and $0.05 \%(\mathrm{v} / \mathrm{v})$ Tween $20, \mathrm{pH}=7.4)$ through the column, the resin-bounded recombinant AAT was eluted with elution buffer $\left(50 \mathrm{mM} \mathrm{NaH}_{2} \mathrm{PO}_{4}, 500 \mathrm{mM} \mathrm{NaCl}, 250 \mathrm{mM}\right.$ imidazole, and $0.05 \%(\mathrm{v} / \mathrm{v})$ Tween 20, $\mathrm{pH}=7.4$ ).

\section{NBT}

Dopa, a hydroxylated form of tyrosine, has a key role for adhesion in underwater conditions because of its reversible adhesive properties and strong non-covalent bond with half-strong covalent bonding with a wet metal oxide surface (Rahimnejad et al.2017). We wanted to know about the conversion of tyrosine to dopa. Since it is responsible for directly adhering proteins to a different surface, the conversion of tyrosine to dopa during post-translational modification is important. Because dopa and dopaquinone can be detected by redox cling staining using glycine and NBT, the NBT staining method is widely used for detecting dopa in MAPs (Zhang et al.2017). Unmodified E. coli derived Mfp5- CsgA and Mfp3GvpA (Mfp5- CsgA and Mfp3- GvpA before expiration in Pichia pastoris) and in vitro tyrosinase modified Pichia pastoris derived Mfp5- CsgA and Mfp3- GvpA were used as negative and positive controls, respectively. Although all protein bands were clearly detected by Coomassie staining (Figure 3 ), the bands of P. pastoris-derived Mfp5- CsgA and Mfp3- GvpA and modified E. coli-derived fp-151 (Figure 3) were observed on NBT-stained AU-PAGE except for unmodified E. coli-derived Mfp5-CsgA and Mfp3-GvpA. Thus, we were convinced that recombinant MAP from Pichia pastoris in vivo-modified dopa.

\section{Mass spectrometry}


Matrix-assisted laser desorption/ionization time-of-flight (MALDI-TOF) mass spectrometry was performed using an ultra-flex treme mass spectrometer (Bruker, Leiderdorp, the Netherlands). Proteins were desalted using Micro Bio-Spin P-6 columns (Bio-Rad, Veenendaal, The Netherlands), and samples were prepared by the dried droplet method on a $600 \mu \mathrm{m}$ Anchor Chip target (Bruker, Leiderdorp, The Netherlands), using $8 \mathrm{mg} \mathrm{mL}^{-1}$ 2,5-dihydroxyacetophenone, $1.5 \mathrm{mg} \mathrm{mL}^{-1}$ diammonium hydrogen citrate, $25 \%$ (v/v) ethanol and $3 \%(\mathrm{v} / \mathrm{v})$ trifluoroacetic acid as matrix. Spectra were derived from ten $500-$ shot $(1000 \mathrm{~Hz})$ acquisitions taken at non-overlapping locations across the sample. Wide mass-range measurements were made in the positive linear mode, with ion source 1, $25.0 \mathrm{kV}$; ion source 2, $23.3 \mathrm{kV}$; lens, $6.5 \mathrm{kV}$; pulsed ion extraction, $680 \mathrm{~ns}$. Detailed analyses of glycoproteins in the $\sim 31-51 \mathrm{kDa}$ range were done with ion source 1, $20.0 \mathrm{kV}$; ion source 2, $18.4 \mathrm{kV}$; lens, $6.2 \mathrm{kV}$; pulsed ion extraction, $450 \mathrm{~ns}$, and spectra were derived from ten 1000-shot $(1000 \mathrm{~Hz})$ acquisitions. Protein Calibration Standard II (Bruker, Leiderdorp, The Netherlands) was used for external calibration.

\section{Surface analysis}

Surface topography and mean average surface roughness ( $\mathrm{Ra}$ ) were examined by atomic force microscopy (AFM) (DMEDualscope c-26, Denmark). To perform the surface topography test, we tested samples Mfp3- GvpA and Mfp5-CsgA in both pH 2.6 and pH 5.5. For this purpose, 20 microliters of the purified samples of Mfp3-GvpA and Mfp5-CsgA was poured onto the mica surface with $1 \mathrm{M}$ acetic acid and placed in an AFM device after drying. In two pH 2.6 and 5.5 (Huang et al.2012; Urushida et al .2007).

Table 1. Oligonucleotide sequences designed as the and reverse primers for the Mfp5-CsgA and Mfp3GvpA genes.

\begin{tabular}{|ll|}
\hline Primer & Sequence \\
\hline Forward Mfp5-CsgA & 3'GACTGGTTCCAATTGACAAGC5' \\
\hline Reverse Mfp5-CsgA & 5'GCAAATGGCATTCTGACATCC3' \\
\hline Forward Mfp3-GvpA & 3'GACTGGTTCCAATTGACAAGC5' \\
\hline Reverse Mfp3-GvpA & 5'GCAAATGGCATTCTGACATCC3 ' \\
\hline
\end{tabular}

\section{Results}

\section{Genomic Integration of the PPICZa vector}

MPF5-CsgA and MPF3-GvpA genes were cloned into the yeast cell of Pichia pastoris and produced the desired proteins. After enzymatic digestion, and two 750 bp bands (Gene) and 2000bp (pPICZa vector) were observed (Fig. 1).

\section{SDS page Analysis}


HIS-Tag purification gave a purity of _90\% for hybrid Mfp-CsgA and Mfp- GvpA (Figure 2). The presence of Mfp in each collected medium sample was confirmed by SDS page analysis.

\section{Western and Analysis}

HisTag purification gave a purity of _90\% for hybrid Mfp-CsgA and Mfp- GvpA (Figure 3). The presence of Mfp in each collected medium sample was confirmed by Western analysis. The Western blotting with specific polyclonal antibodies for each Mfp revealed two bands of approximately 32 and $31 \mathrm{kDa}$.

\section{Mass spectrometry Analysis}

The MALDI-TOF analysis confirms the conclusion from SDS-PAGE that the Mfp3-GvpA is pure and intact. However, The MALDI-TOF spectrum for Mfp5 CsgA (Figure 4) showed several peaks. The minor low mass peak at $\mathrm{m} / \mathrm{z} 32,273$ and 31,174 is in accordance with the expected molecular weight of the intact protein (31-32 KDa). This size of adhesive protein has been confirmed in other studies (Mori et at.2017; Werten et al. 2019). The maximum concentration of hybrid MPF 5- CsgA and MPF 3- GvpA expressed was $185 \mathrm{lg} / \mathrm{mL}$ in the $500-\mathrm{mL}$ spinner flask culture.

\section{Dopa modification}

As shown in figure 5 of NBT, all of the samples expressed in P. pastoris produced purple color during the conversion of tyrosine to dopa (Mattanovich et al .2009).

In this test, we also showed our umodified samples of lack of expression in Pichia pastoris cells in which tyrosin had not converted to dopa, resulting in the absence of purple color.

It is worth mentioning that the samples observed in Figures $C$ and $D$ result from the expression of the above proteins in the bacterial host. Proteins that expressed in bacteria were not modified and consequently their tyrosine does not convert into dopa. This test confirms the use of yeast host cells to express adhesive proteins containing dopa compared to that of expressed in prokaryotic hosts.

\section{Adhesion ability}

AFM revealed the surface morphology of Mfp3- GvpA and Mfp5- CsgA .Figur 5 shows topography image Mfp3-GvpA structure and Mfp3-GvpA in pH5.5, respectively. Figure5D shows the 3D image of Mfp3GvpA. As can be seen from the topographic images, the size of the Mfp5- CsgA proteins is larger than Mfp3GvpA and these proteins have larger volume of tissue. Besides the phase and topographic images of protein Mfp5-CsgA and Mfp3-GvpA in the co-polymer state, Mfp5-CsgA has larger structure compared to Mfp3-GvpA as well as requiring more energy for separation from the mica surface. This indicates that the adhesion force of Mfp5-CsgA is stronger than Mfp3-GvpA and the adhesion force in the polymer is far greater than that of protein Mfp3-GvpA. Also, the above proteins in acidic pHs had more cohesion and density than other $\mathrm{pHs}$. 


\section{Discussion}

The production of feasible and functional bio-adhesives with the ability to attach to wet surfaces is still one of the great challenges in the biomedicine industry. that play a key role in biofilm structure and adhesion to various surfaces. Various adhesive materials have been reported so far, but none of the products produced have been able to meet all the necessary needs. In the present study, the recombinant protein expressed in terms of the post-translational process was approved. Similar studies have also shown that Pichia pastoris, as a host, exhibits good expression of extracellular proteins mainly owing to post translation modification and higher expression levels (Rueda et al .2016; Zhu et al. 2018). The current study provides the first report of utilizing the yeast expression system to generate multiplex combinational fusion protein composed of Mfp3, Mfp5, GvpA, and CsgA proteins. Of course, previous studies have reported the production of adhesive proteins in bacterial hosts, but the weakness of the bacterial system is the post-translational process (Waite 2017; Zhang et al .2017). An important advantage of a fungal host is the post-translational process, such as proper glycosylation and secretion of protein into the culture medium.

In prevailing literature, the role of dopa as the main constituent for adhesion of mussel foot proteins has been reported (Mirshafian et al .2016; Visekruna et al .2014). In the present study, we exploited Mfp-5 and Mfp-3as a prominent part of the chimeric protein structure mainly due to their tyrosine residues present in the protein sequence that transform into dopa for adhesion. Similar Studies have shown that these two proteins together can produce resistant bio-adhesive (Rubin et al. 2010) and proposed that they can be considered as favorable candidates for medical applications owing to their non-toxicity and weak immune response inductions (Zhang et al. 2017). However, produced recombinant bio-glues are not mature enough and suffer from weak bonds, high cost, or low safety for clinical applications (Forooshani et al. 2017). The production of novel recombinant proteins by combining them with curli adhesive fibers has been suggested as an efficient strategy for gaining better attachment and conjugation for better adhesion to reach regenerative medicine market needs (Huang et al .2012).

We used the CsgA sequence from E. coli along with CsgA, another curli protein from Cyanobacteria, to improve adherence of Mfp3 and five other proteins. As the origin of CsgA sequence could be pathogenic, it may cause allergic sensitivities. Thus, we have assessed using another curli protein, GvpA, from nonpathogenic curli protein derived from cyanobacteria.

In order to improve the performance of bio-adhesive in the present study, the curli sequence of proteins along with the main sequence of mussel foot adhesive proteins was used. Zhong et al. obtained a new bio-adhesive protein by inserting the Mfp3-CsgA and mfp5- CsgA genes through a single-step assembly into a bacterial cell. Mfp3- CsgA and Mfp5- CsgA were converted into fibril bundles due to their amyloid filaments, and the adhesive strength of this type of bi-adhesive in seawater was $20.9 \mathrm{~mJ} \mathrm{~m}-2$, which was about 1.5 times higher than the ability of recombinant bi-adhesives produced at that time. The addition of cross-links to the adhesive structure can improve adhesion and its survival. Among the natural compounds that can be used as crosslinkers is the helix of the proteins of early bacteria and $E$. coli. 
Preliminary simulations of molecular dynamics have been shown. The recombinant protein Mfp-5-CsgA has the ability to form a stable $\beta$ structure in an aqueous solution so that Mfp will be present in the amyloid regions of CsgA in the central part (Waite et al .2001).

The main practical challenges for expressing adhesive proteins are low solubility of the purified protein eir large-scale production (Wang et al.2020; Stewart et al .2011). Exploiting fungal hosts such as yeast instead of prokaryotic systems has been reported for various proteins expression without any allergic response in human body (Huang et al .2012). To address the aforementioned problems, we have used $P$. pastoris as a host for expression of the chimeric protein due to its higher production rates with better post translational modifications necessary for efficient function of the obtained protein. Though there is definitely no ideal host for adhesive protein expression, our research shows that Pichia pastoris seems to be a quite suitable host due to the high glycosylation.

On the other hand, the structure and combinational features of chimeric proteins have a significant role in their characteristics (George et al.2018). During the present study, the factors that have affected the efficiency and affinity of recombinant protein expression have been considered. Various culture conditions such as media component, temperature, $\mathrm{pH}$, and incubation time have been modified to improve expression. Data obtained here showed that expression of chimeric protein in lower temperature $\left(25-26^{\circ} \mathrm{C}\right)$ and adding $40 \%$ more YNB culture medium into the main culture medium (BMY) was more efficient approach for protein expression than prevailing approaches such as stated in Invitrogen protocol (Safder et al .2018). It might be due to the positive effect of low temperature and nutritional supplementation on protein expression and could be considered for large-scale heterogeneous protein performance (Silverman et al.2017; Mori et al. 2017; Wang et al .2020)

One of the major challenges in producing bio-adhesives from mussel foot proteinosis is adhesive proteins demonstrating resistance at a particular $\mathrm{pH}$. In the present study, AFM microscopic images also show greater cohesion of proteins in acidic $\mathrm{pH}$.

So far, many attempts have been made to produce bio-adhesives based on mussel foot proteins, but which protein is really the best choice for making bio-adhesives. Here, we used proteins Mfp3 along with curli GvpA proteins and also proteins Mfp5 along with curli CsgA proteins. AFM microscopic images show the strength and coherence of each of these proteins alone are acidic in $\mathrm{pH}$. But what matters is the images resulting from the combination of proteins Mfp3 and Mfp5 each of which has a large number of dopa next to Curli Protein. It produces chimeric recombinant proteins with greater coherence. Altogether, it can be concluded that obtained adhesion strength of chimeric protein Mfp3 and Mfp5 with curli protein including CsgA and GvpA was significantly higher than that of native Mfp proteins, majorly owing to the improved cross linking in recombinant $\mathrm{mfp}-3$ and $\mathrm{mfp}-5$ proteins by curli proteins. Due to the good posttranslational changes that take place in the P. pastoris cell. P. pastoris yeast cells have the potential to be a favorable host cell to produce Mfp 3, Mfp 5, CsgA and GvpA on a large scale. The adhesion of chimeric proteins was much higher than that of non-chimeric proteins. The production of protein with appropriate function can be used in medicine, dentistry, and biotechnology in various fields. 


\section{Declarations}

\section{Acknowledgments}

Authors would like to express our sincere gratitude to Mr. Keyvan Shahryarimorad, Dr. Atefeh Alipour and Dr. Mohammadali Shokrgozar for their helpful discussion and suggestions during experiments and manuscript preparation.

\section{Authors' contributions}

HS and MA conceived and designed the study while HS supervised the main project. NB performed the experiments and collected the data. NB and HS performed experimental data analysis. NB wrote initial draft and all co-authors discussed the results and contributed to critical revision of the final manuscript.

\section{Funding}

This work is partially supported by grant in aid from Iran National Science Foundation (INSF) to HS (grant No: 96016699).

\section{Availability of data and materials}

Not applicable.

\section{Ethical Statement}

This article does not contain any studies with human participants or animals performed by any of the authors.

\section{Consent for publication}

Not applicable.

\section{Competing interests}

The authors declare no competing financial/non-financial interests.

\section{References}

Waite JH, Qin X (2001) Poly phosphoprotein from the adhesive pads of Mytilus edulis. Biochemistry 40(9):2887-93

Dolgin E (2013) The sticking point. Nat Med 19:124-125

Choi YS, Kang DG, Lim S, Yang YJ, Kim CS, Cha HJ (2011) Recombinant mussel adhesive protein fp-5 (MAP fp-5) as a bulk bio-adhesive and surface coating material. Biofouling 27(7):729-37 
Deming TJ. Mussel (1999) byssus and biomolecular materials. Current opinion in chemical biology. Curr Opin Chem Biol 3(1):100-5

Priemel T, Degtyar E, Dean MN, Harrington MJ (2017) Rapid self-assembly of complex biomolecular architectures during mussel byssus bio fabrication. Nat. Commun 8:14539

Yu J, Wei W, Menyo MS, Masic A, Waite JH, Israelachvili JN (2013) Adhesion of mussel foot protein-3 to TiO2 surfaces: the effect of $\mathrm{pH}$. Biomacromol 14(4):1072-7

Rzepecki LM, Hansen KM, Waite JH (1992) Characterization of a cystine-rich polyphenolic protein family from the blue mussel Mytilus edulis. Biol. Bull. 183(1):123-37

Waite JH (2017) Mussel adhesion essential footwork. J Exp Biol 220(4):517-30

Zhao $\mathrm{H}$, Waite $\mathrm{JH}$ (2006) Linking adhesive and structural proteins in the attachment plaque of Mytilus californianus. J Biol Chem. 281(36):26150-8

Jeon EY, Hwang BH, Yang YJ, Kim BJ, Choi BH, Jung GY, Chai HJ (2015) Rapidly light activated surgical protein glue inspired by mussel adhesion and insect structural crosslinking. Biomaterials 67:11-9

Zhang X, Huang Q, Deng F, Huang H, Wan Q, Liu M, Wei Y (2017) Mussel-inspired fabrication of functional materials and their environmental applications: Progress and prospects. Appl Mater Today 7:222-38

Rahimnejad M, Zhong W (2017) Mussel-inspired hydrogel tissue adhesives for wound closure. RSC Adv 7(75):47380-96

Rebnegger C, Graf AB, Valli M, Steiger MG, Gasser B, Maurer M (2014) In Pichia pastoris, growth rate regulates protein synthesis and secretion, mating and stress response. Biotechnol J 9(4):511- 25

Pfeifer, F. (2012) Distribution formation and regulation of gas vesicles. Nat Rev Microbiol 10:705-715

Hayes PK, Buchholz B, Walsby AE. (1992) Gas vesicles are strengthened by the outer-surface protein Gvp C. Arch Microbiol 157:234-229

Mattanovich D, Graf A, Stadlmann J, Dragosits M, Redl A, MaurerM (2009) Genome, secretum and glucose transport highlight unique features of the protein production host Pichia pastoris. Microb Cell Fact. 1475:2859-8-29.

Waite JH (1995) Precursors of quinone tanning dopa-containing proteins. Method Enzymol 258:1-20

Aitken R J, Smith TB, Jobling MS, Baker MA, De luliis GN (2014) Oxidative stress and male reproductive health. Asian J Androl 16: 31-38 
Yu J, Wei W, Danner E, Israelachvili JN, Waite JH (2011) Effects of interfacial redox in mussel adhesive protein films on mica. Adv Mater 23:2362- 2366

Huang Y, Zhang Y, Wu Y, Wang J, Liu X, Dai L (2012) Expression, purification, and mass spectrometric analysis of $15 \mathrm{~N}, 13 \mathrm{C}$-labeled RGD hirudin, expressed in Pichia pastoris, for NMR studies. PLoS One7(8): e42207

Urushida Y, Nakano M, Matsuda S, Inoue N, Kanai S, Kitamura N (2007) Identification and functional characterization of a novel barnacle cement protein. FEBS J 274: 4336-4346

Mori Y, Urushida Y, Nakano M, Uchiyama S, Kamino K (2007) Calcite-specific coupling protein in barnacle underwater cement. FEBS J 274: 6436-6446

Werten MWT, Eggink G, Cohen Stuart MA, de Wolf FA (2019) Production of protein-based polymers in Pichia pastoris. Biotechnol Adv 37(5):642-666

Rueda F, Gasser B, Sanchez-Chardi A, Roldan M, Villegas S, Puxbaum V, Ferrer-Miralles N, Unzueta U, Vazquez E, Garcia-Fruitos E, Mattanovich D, Villaverde A (2016) Functional inclusion bodies produced in the yeast Pichia pastoris. Microb Cell Fact 15:166.

Zhu W, Chuah Y J, Wang D A (2018) Bio-adhesives for internal medical applications: A review. Acta Biomat 74:1-16.

Zhang W, Yang H, Liu F, Chen T, Hu G, Guo D, Hou Q, Wu X, Su Y,Wang J (2017) Molecular interactions between DOPA and surfaces with different functional groups. a chemical force microscopy study. RSC Adv 7: 32518-32527

Mirshafian R, Wei W, Israelachvili JN, Waite J H (2016) a, $\beta$-Dehydro-Dopa: a hidden participant in mussel adhesion. Biochemistry 55: 743-750

Visekruna A, Linnerz T, Martinic V, Vachharajani N, Hartmann S, Harb H (2014) Transcription factor c-Rel plays a crucial role in driving antiCD40-mediated innate colitis. Mucosal Immunol 8(2):307-15

Rubin DJ, Miserez A,Waite JH (2010) Diverse strategies of protein sclerotization in marine invertebrate structure-property relationships in natural biomaterials. Adv Insect Physiol 38:75-133

Forooshani P, Lee B (2017) approaches in designing bio adhesive materials inspired by mussel adhesive protein. Pol Chem 55(1):9-33

George MN, Carrington E (2018) Environmental post-processing increases the adhesion strength of mussel byssus adhesive. Biofouling 34:388-397

Baumann K, Dato L, Graf AB, Frascotti G, Dragosits M, Porro D (2011) The impact of oxygen on the transcriptome of recombinant $S$. cerevisiae and $P$. pastoris a comparative analysis. BMC Genomics 
12(1):218

Arava Y, Wang Y, Storey JD, Liu CL, Brown PO, Herschlag D (2003) Genome-wide analysis of mRNA translation profiles in Saccharomyces cerevisiae. Proc Natl Acad Sci USA 100(7):3889-3894

Lee H, Rho J, Messsersmith PB (2009) Facile conjugation of biomolecules onto surfaces via mussel adhesive protein inspired coatings. Adv. Mater. 26:431-434

Silverman HG, Roberto FF (2007) Understanding marine mussel adhesion. Mar Biotechnol 9: 661-681

Urushida Y, Nakano M, Matsuda S, Inoue N, Kanai S, Kitamura N, Nishino T, Kamino K (2007) Identification and functional characterization of a novel barnacle cement protein. FEBS J 274:4336-4346

Mori Y, Urushida Y, Nakano M, Uchiyama S, Kamino K (2007) Calcite-specific coupling protein in barnacle underwater cement. FEBS J 274:6436-6446

Hennebert E, Maldonado B, Van de Weerdt C, Demeuldre M, Richter K, Rischka K, Flammang P (2015) From sand tube to test tube: the adhesive secretion of Sabellariid tubeworms. In Bio-adhesion and biomimetics from nature to applications. Pan Stanford 77:105-123

Geurts P, Zhao L, Hsia, Tang S, Jeffery F, Mattina C, Franz A, Larkin L, Vierra C (2010) Synthetic spider silk fibers spun from Pyriform Spidroin 2, a glue silk protein discovered in orb-weaving spider attachment discs. Biomacromol 11: 3495-3503

Wang Q, Chao Z, Xiao H (2020) Genetic engineering of filamentous fungi for efficient protein expression and secretion. Front Bioeng Biotechnol 8.293

Stewart R J (2017) Protein-based underwater adhesives and the prospects for their biotechnological production. Appl Microbiol Biotechnol 89(1):27-33

Safder I, Sajad KH, Iram US, Muhammad K (2018) Pichia pastoris expression system: a potential candidate to express protein in industrial and biopharmaceutical domains. Biomed Lett 4(1): 1-13

\section{Figures}



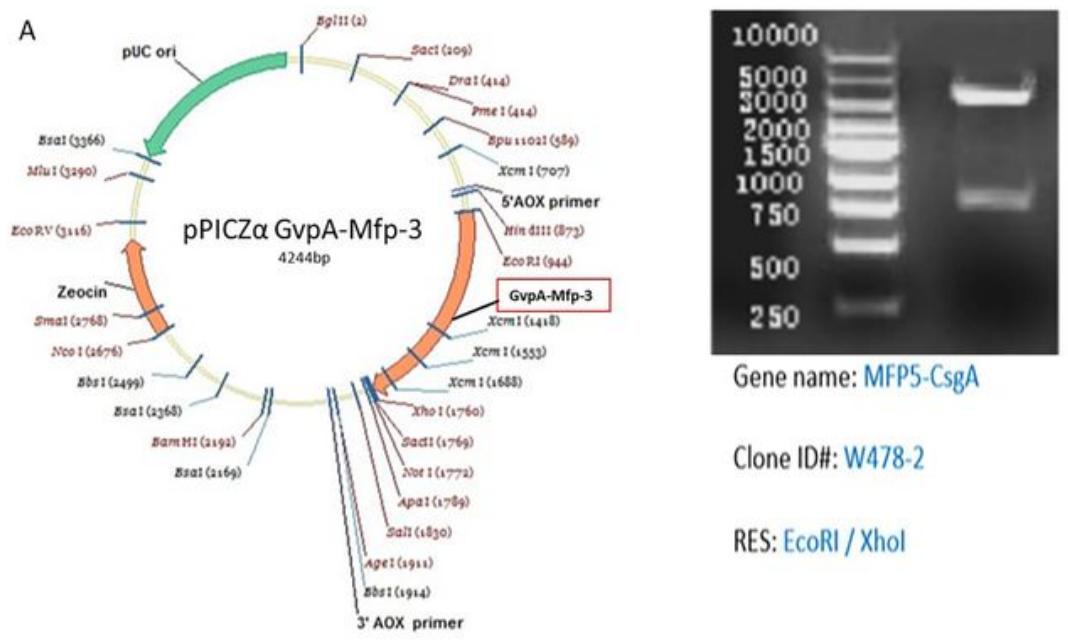

Gene name: MFP5-CsgA

Clone ID\#: W478-2

RES: EcoRI/ Xhol
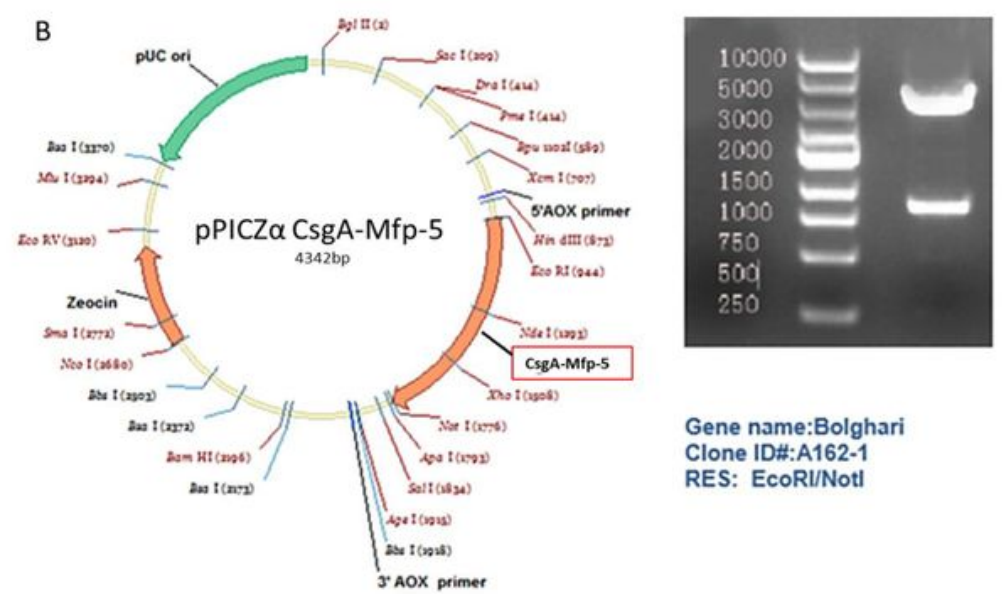

Gene name:Bolghari

Clone ID\#:A162-1

RES: EcoRI/Notl

$C$

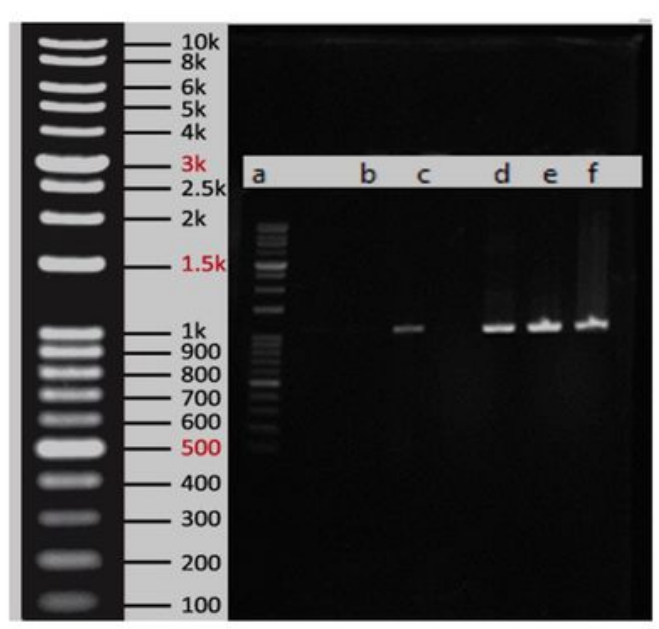

\section{Figure 1}

Map of the pPICZa A -GvpA-Mfp-3 (A)and pPICZa A -CsgA-Mfp-5 plasmid construction(B). Gene sequences were inserted between EcoRI and Xhol, EcoRI and Notl restriction sites, respectively. Proof of the successful transfection and presence of the desired chimeric gene in yeast by PCR amplification(C) 
A

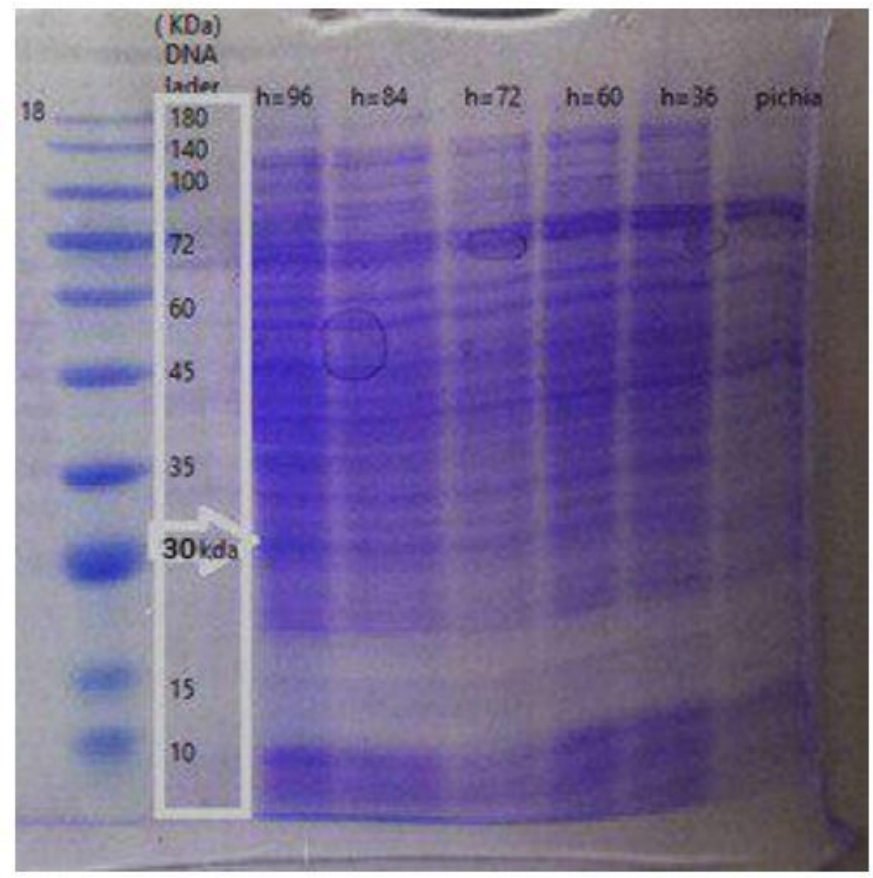

B

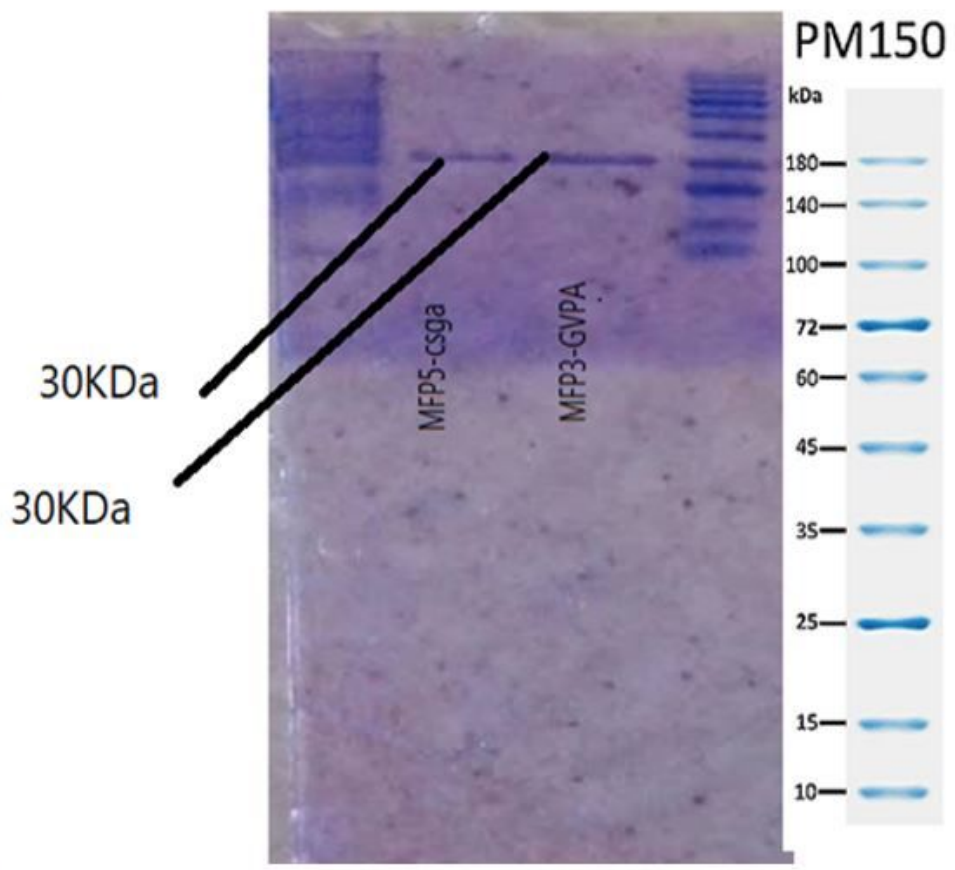

Figure 2

SDS-PAGE analysis for purified fused recombinant proteins before and after purification (A and B).

A

GvpA-Mfp-3

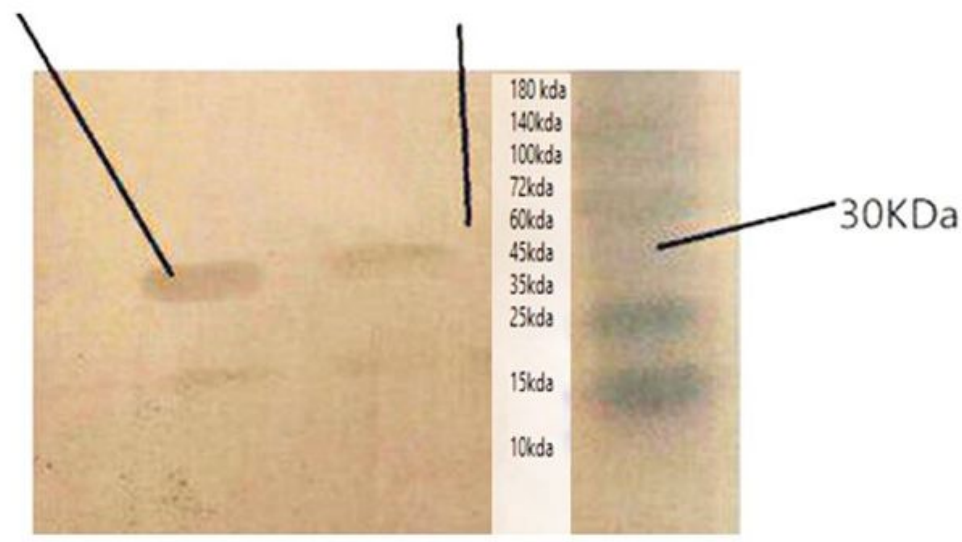

B

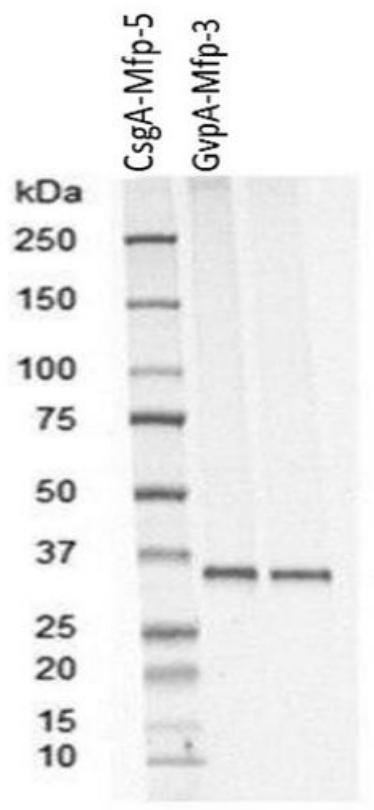

\section{Figure 3}

Western blotting analysis for recombinant chimeric proteins before and after purification ( $A$ and $B$ ). 

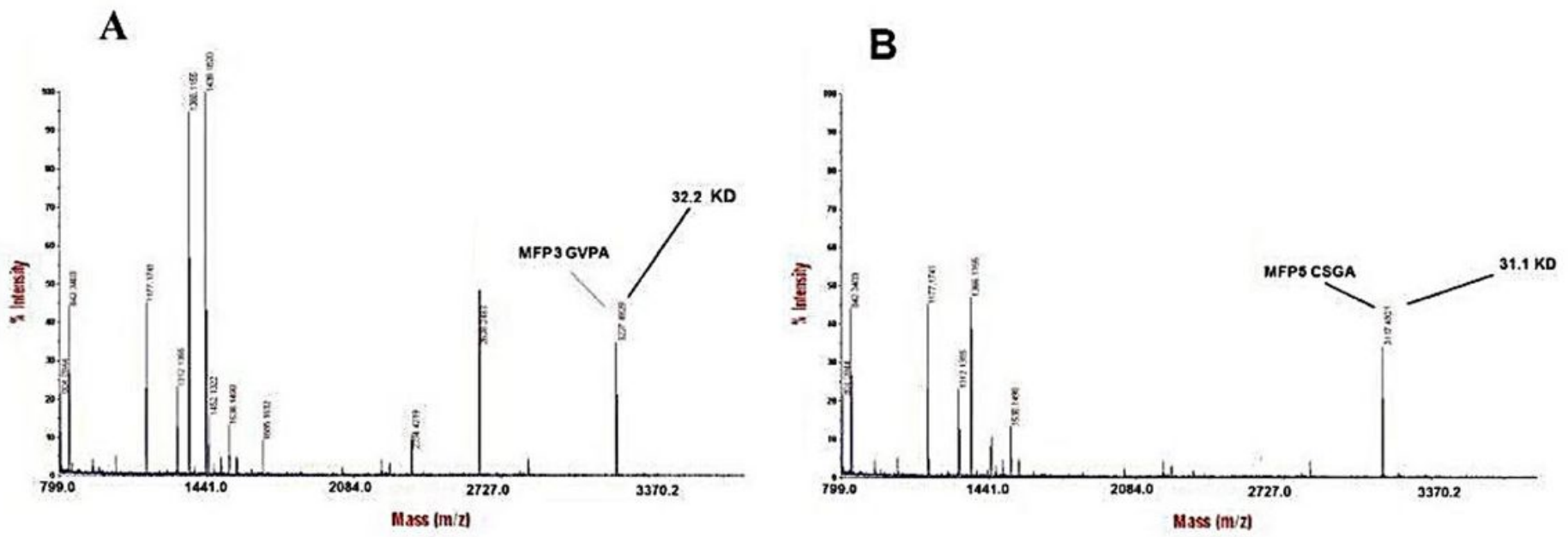

Figure 4

Purity and molecular weight of the adhesive proteins were determined by MS. MALDI-TOF analysis. A) Mfp3-GvpA B) Mfp5- CsgA. 


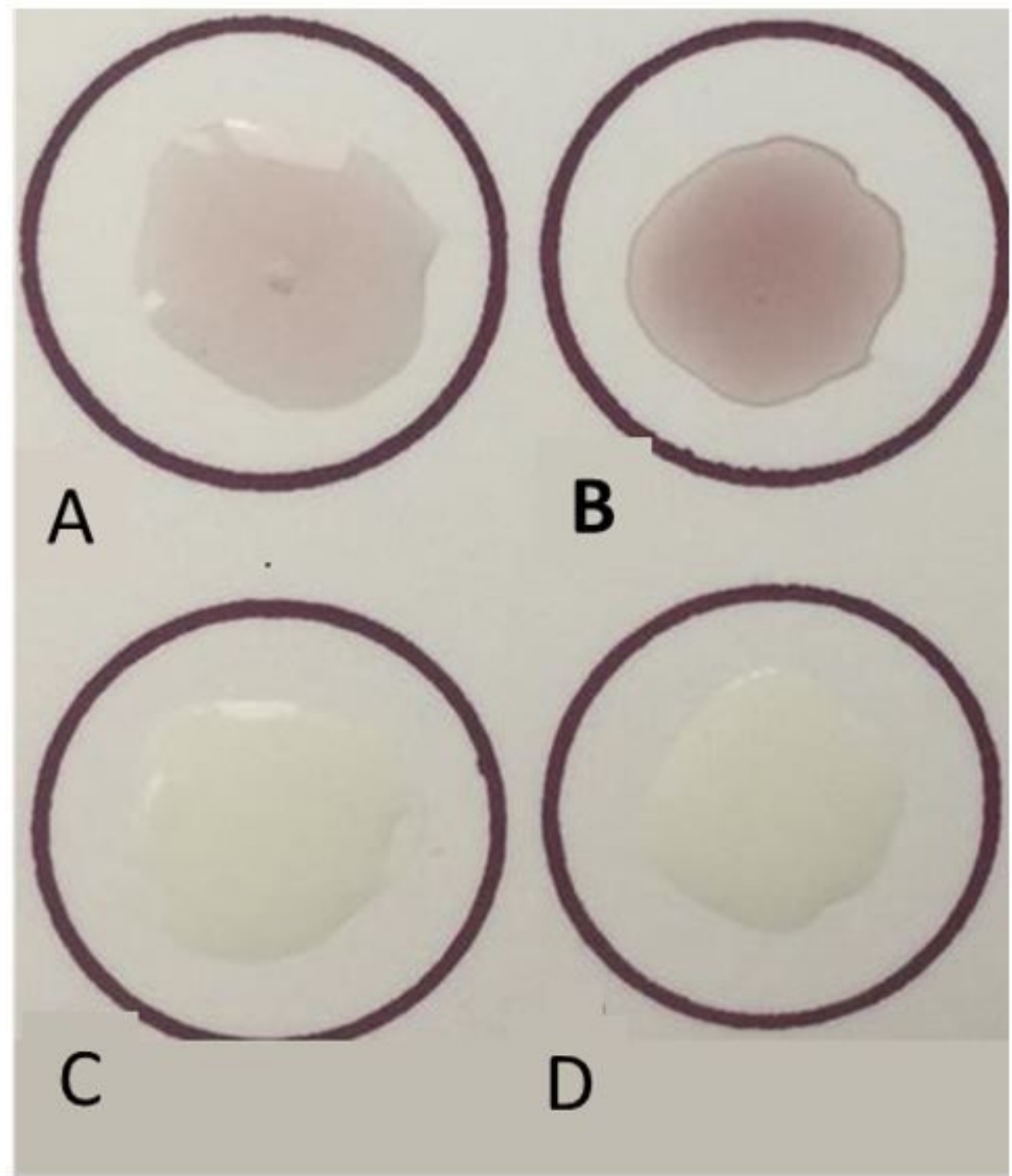

Figure 5

Redox-cycling nitrobluetetrazolium (NBT) assay for recombinant chimeric Mfp3-GvpA and Mfp-3-GvpA adhesive proteins (100 $\mu \mathrm{L}$ of $40 \mu \mathrm{g} / \mathrm{mL}$ ). A) Mfp3-GvpA after modification B) Mfp5-CsgA after modification. C) Mfp3-GvpA before modification. D)Mfp5-CsgA before modification. 

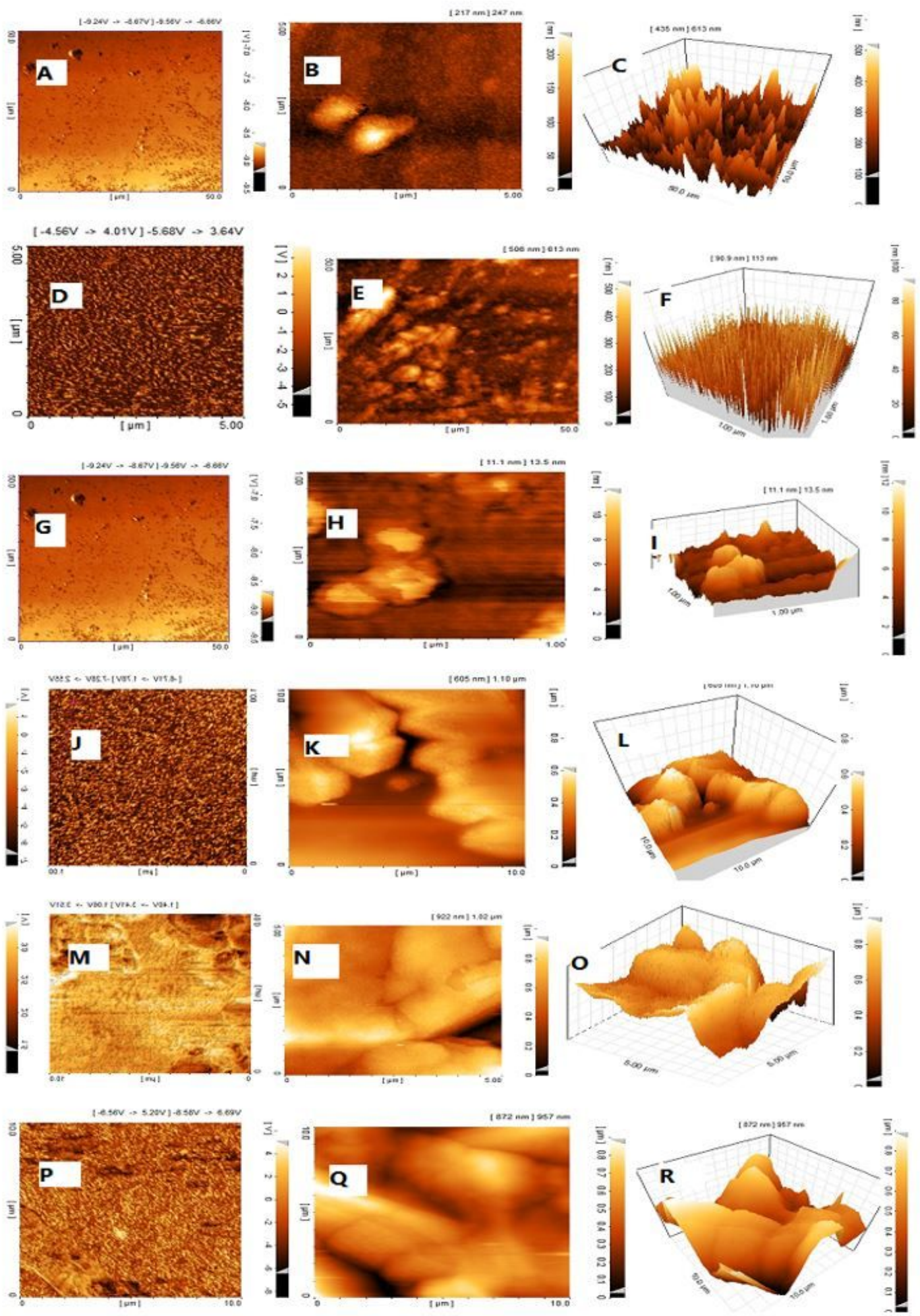

\section{Figure 6}

Surface morphology of Mfp3- GvpA and Mfp5- CsgA A) Phase image of protein Mfp3- GvpA in PH 5.5 B) topography image of Mfp 3- GvpA in pH5.5 C) 3D image of Mfp 3 GvpA in pH 5.5 D) Phase image of protein Mfp 3-GvpA in pH 2.6 E) topography image of Mfp 3-GvpA in pH2.6 F) 3D image of Mfp 3GvpA IN $\mathrm{PH}$ 2.6.G) Phase image of protein Mfp 5- CsgA in pH 5.5 H) topography image of Mfp 5-CsgA in pH5.5 I) 3D image of Mfp 5-CsgA in pH 5.5 J) Phase image of protein Mfp 5-CsgA in pH $2.6 \mathrm{~K}$ ) topography image 
of Mfp 5-CsgA in pH2.6 L) 3D image of Mfp 5- CsgA IN pH 2.6 M) Phase image of protein Mfp 3-GvpA and Mfp 5-CsgA in pH 5.5 N) ) topography image of Mfp 3-GvpA and Mfp 5-CsgA in pH5.5 0) 3D image of Mfp 3GvpA- Mfp 5-CsgA in pH 5.5 P) Phase image of protein Mfp 3-GvpA and Mfp 5-CsgA in pH 2.6 Q) topography image of Mfp 3-GvpA and Mfp 5-CsgA in pH 2.6 R) 3D image of Mfp 3GvpA-Mfp 5-CsgA in $\mathrm{pH} 2.6$

\section{Supplementary Files}

This is a list of supplementary files associated with this preprint. Click to download.

- GraphicalabstractBolghari.pptx.docx 